Article

\title{
The Cardiovascular and Neurotoxic Effects of the Venoms of Six Bony and Cartilaginous Fish Species
}

\author{
Han Han ${ }^{1,+}{ }^{\dagger}$, Kate Baumann ${ }^{2,+}$, Nicholas R. Casewell ${ }^{3,+}$, Syed A. Ali ${ }^{1,4,+}$, James Dobson ${ }^{2}$, \\ Ivan Koludarov ${ }^{2}$, Jordan Debono ${ }^{2}$, Scott C. Cutmore ${ }^{5}$, Niwanthi W. Rajapakse ${ }^{6,7}$, \\ Timothy N. W. Jackson ${ }^{2}$, Rob Jones ${ }^{8}$, Wayne C. Hodgson ${ }^{1}$, Bryan G. Fry ${ }^{2, *}$ \\ and Sanjaya Kuruppu ${ }^{1,9, *}$
}

1 Department of Pharmacology, Biomedicine Discovery Institute, Monash University, Clayton, VIC 3800, Australia; hhan24@student.monash.edu (H.H.); dr.syedabidali@gmail.com (S.A.A.); wayne.hodgson@monash.edu (W.C.H.)

2 Venom Evolution Lab, School of Biological Sciences, University of Queensland, St Lucia, QLD 4072, Australia; kate.baumann@uqconnect.edu.au (K.B.); james.dobson@uqconnect.edu.au (Jam.D.); ivan.koludarov@uq.net.au (I.K.); jordan.debono@uqconnect.edu.au (Jor.D.); tnwjackson@gmail.com (T.N.W.J.)

3 Alistair Reid Venom Research Unit, Liverpool School of Tropical Medicine, Pembroke Place, Liverpool L3 5QA, UK; nicholas.casewell@lstmed.ac.uk

4 HEJ Research Institute of Chemistry, International Centre for Chemical and Biological Sciences (ICCBS), University of Karachi, Karachi 75270, Pakistan

5 Marine Parisitology Group, School of Biological Sciences, University of Queensland, St Lucia, QLD 4072, Australia; scott.cutmore@uqconnect.edu.au

6 Baker IDI Heart and Diabetes Institute, 75 Commercial Road, Prahran 3181, Australia; niwanthi.rajapakse@bakeridi.edu.au

7 Department of Physiology, Biomedicine Discovery Institute, Monash University, Clayton, VIC 3800, Australia

8 The Aquarium Vet, P.O. Box 2327, Moorabbin, VIC 3189, Australia; rob@theaquariumvet.com.au

9 Department of Biochemistry \& Molecular Biology, Biomedicine Discovery Institute, Monash University, Monash, VIC 3800, Australia

* Correspondence: bgfry@uq.edu.au (B.G.F.); sanjaya.kuruppu@monash.edu (S.K.); Tel: +61-4-0019-3182 (B.G.F.); +61-3-9902-9372 (S.K.)

+ These authors contributed equally to this work.

Academic Editor: Angel A. Yanagihara

Received: 15 September 2016; Accepted: 3 February 2017; Published: 16 February 2017

\begin{abstract}
Fish venoms are often poorly studied, in part due to the difficulty in obtaining, extracting, and storing them. In this study, we characterize the cardiovascular and neurotoxic effects of the venoms from the following six species of fish: the cartilaginous stingrays Neotrygon kuhlii and Himantura toshi, and the bony fish Platycephalus fucus, Girella tricuspidata, Mugil cephalus, and Dentex tumifrons. All venoms (10-100 $\mu \mathrm{g} / \mathrm{kg}$, i.v.), except G. tricuspidata and P. fuscus, induced a biphasic response on mean arterial pressure (MAP) in the anesthetised rat. P. fucus venom exhibited a hypotensive response, while venom from $G$. tricuspidata displayed a single depressor response. All venoms induced cardiovascular collapse at $200 \mu \mathrm{g} / \mathrm{kg}$, i.v. The in vitro neurotoxic effects of venom were examined using the chick biventer cervicis nerve-muscle (CBCNM) preparation. N. kuhlii, $H$. toshi, and P. fucus venoms caused concentration-dependent inhibition of indirect twitches in the $\mathrm{CBCNM}$ preparation. These three venoms also inhibited responses to exogenous acetylcholine (ACh) and carbachol $(\mathrm{CCh})$, but not potassium chloride $(\mathrm{KCl})$, indicating a post-synaptic mode of action. Venom from G. tricuspidata, M. cephalus, and D. tumifrons had no significant effect on indirect twitches or agonist responses in the CBCNM. Our results demonstrate that envenoming by these species of fish may result in moderate cardiovascular and/or neurotoxic effects. Future studies aimed at identifying the molecules responsible for these effects could uncover potentially novel lead compounds for future
\end{abstract}


pharmaceuticals, in addition to generating new knowledge about the evolutionary relationships between venomous animals.

Keywords: venom; fish; cardiovascular; neuromuscular; toxin

\section{Introduction}

Venomous marine fish account for nearly two-thirds of the population of venomous vertebrates, and include stingrays, scorpionfish, zebrafish, stonefish, and some species of shark, catfish, and blenny [1-3]. Fish venoms are thought to have originated on at least 18 occasions via the process of convergent evolution [2-4]. However, while significant research effort has focused on characterising the biological activity of venom from terrestrial animals-particularly snakes-little is known about the composition or biological activity of venom from many species of fish. A main reason that these marine vertebrates remain understudied is the difficulty in obtaining, storing, and extracting venom samples [5]. Nevertheless, marine venoms represent a diverse source of untapped biological compounds which, when considering the utility of toxins isolated from other venomous lineages [6], may be useful as potential research, pharmaceutical, or diagnostic tools.

The majority of venomous fish are sedentary, slow moving, and live in shallow, protected waters [7]. Their venoms are classified as defensive, and are thought to be used much less frequently than those employed by other venomous animals for predatory purposes [8]. Despite their extensive taxonomic diversity at the organismal level, the venom delivery systems used by the majority of fish are similar, and typically consist of dorsal, pectoral, and/or clitheral spines [2,3]. This is perhaps not surprising, as the venoms are almost exclusively used for defence, and such spines are likely to provide a degree of mechanical protection alongside the chemical defences conferred by their toxic secretions. In addition, the pharmacological activities of fish venoms have been postulated to be similar, despite their numerous independent origins. This is perhaps best evidenced by the clinical effects of envenoming, which are often defined as resulting in considerable pain disproportionate to the wound size, although a diverse array of other symptoms such as itching, erythema, and paralysis have been described, resulting in occasional fatalities due to cardiovascular and neurological systemic effects [9-13].

Surprisingly, little research has focused on the pharmacological or compositional nature of fish venoms. One exception to this is that of the stonefish (Synanceia spp.), which due to their medically-important nature have been reasonably well studied in terms of their pharmacology, epidemiology, and clinical aspects of envenoming [14-20]. In the present study, we address the paucity of information surrounding fish venoms by investigating those secretions from a variety of cartilaginous (the blue-spotted stingray Neotrygon kuhlii and the brown whipray Himantura toshi, both family Dasyatidae) and bony fish (the dusky flathead Platycephalus fuscus, family Platycephalidae; the Luderick Bream Girella tricuspidata, family Kyphosidae; the mullet Mugil cephalus, family Mugilidae; and the yellowback seabream Dentex tumifrons, family Sparidae).

\section{Results}

\subsection{Effects of Crude Venoms on the Cardiovascular System}

Venoms of $H$. toshi and $N$. kuhlii (10-100 $\mu \mathrm{g} / \mathrm{kg}$, i.v.) produced a dose-dependent biphasic effect on mean arterial pressure (MAP), consisting of a depressor response, followed by a sustained pressor response (Figure 1a,c). Venom of P. fuscus $(10-100 \mu \mathrm{g} / \mathrm{kg}$, i.v.) only caused a transient depressor response (Figure 1e). All three venoms (10-100 $\mu \mathrm{g} / \mathrm{kg}$, i.v.) had no significant effect on heart rate (Figure 1b,d,f), but caused complete cardiovascular collapse in response to $200 \mu \mathrm{g} / \mathrm{kg}$, i.v. (Figure 1a-f). 
(a)

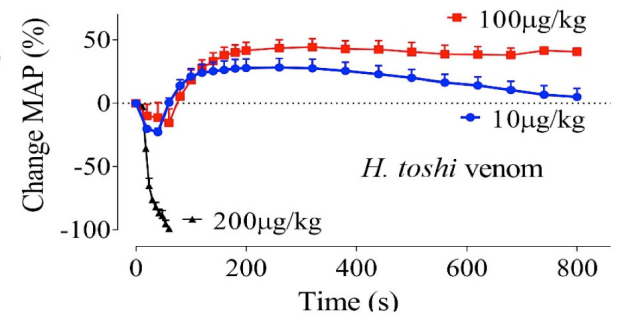

(c)

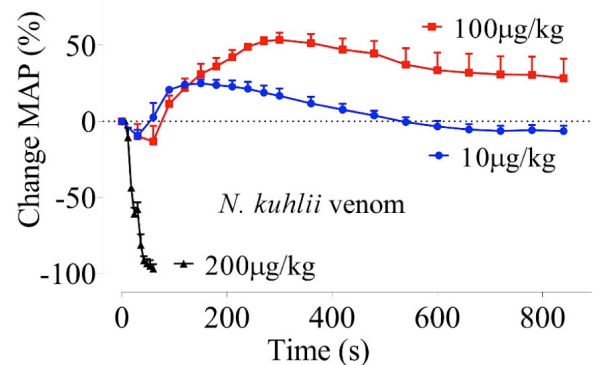

(d)

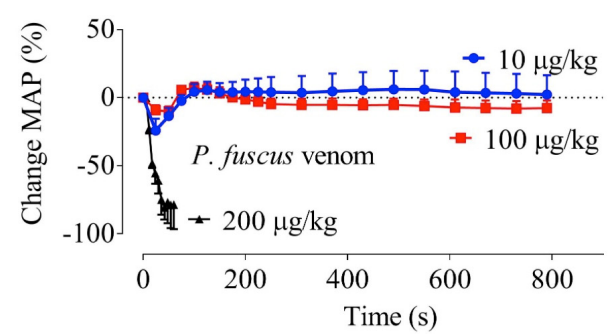

(b)

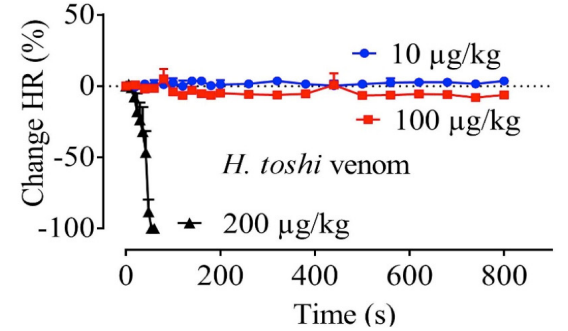

(d)

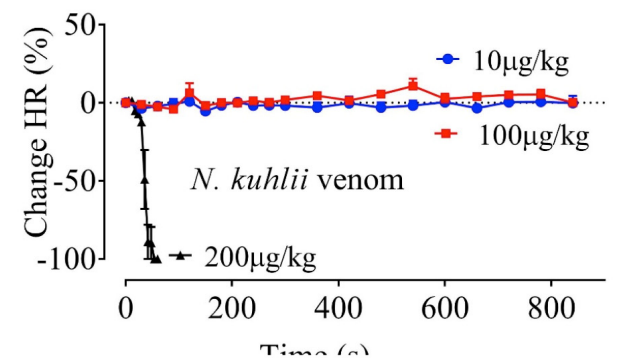

(e)

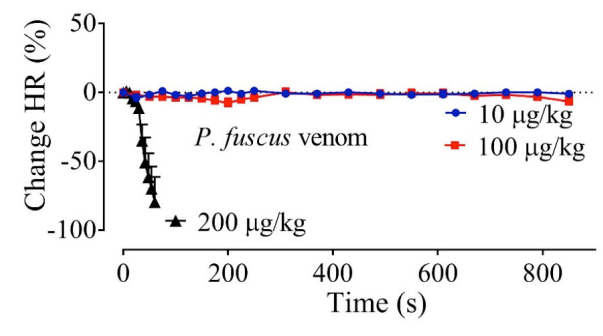

Figure 1. The effect of H. toshi, N. kuhlii, and P. fuscus venoms on mean arterial pressure (MAP; $\mathbf{a}, \mathbf{c}, \mathbf{e}$, respectively) and heart rate (HR; $\mathbf{b}, \mathbf{d}, \mathbf{f}$, respectively) of the anaesthetized rat. $N=4$. Each data point and error bar represents the mean of four experiments and the corresponding SEM, respectively.

Interestingly, the venom of Girella tricuspidata ( $5 \mu \mathrm{g}$ protein $/ \mathrm{kg}$, i.v.) produced a biphasic depressor effect consisting of a transient depressor response, followed by a sustained depressor response (Figure 2a), with no significant effect on HR (Figure 2b). M. cephalus (3 $\mu \mathrm{g} / \mathrm{kg}$, i.v.) and D. tumifrons $(15 \mu \mathrm{g} / \mathrm{kg}$, i.v.) venoms both caused an initial depressor response followed by a pressor response which recovered over time (Figure $2 c, e$ ). In contrast to the stingray venoms, both M. cephalus and D. tumifrons venoms caused small transient decreases in the heart rate of the anaesthetised rat (Figure 2d,f). However, these changes in HR were not significant. The vehicle control group (i.e., saline administration) exhibited no significant effect on either MAP or HR of the anaesthetized rat (data not shown). 
(a)

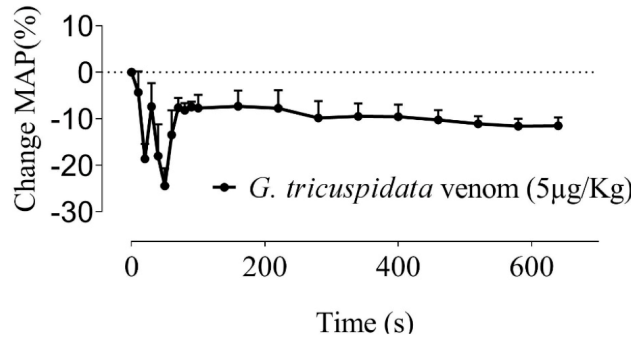

(c)

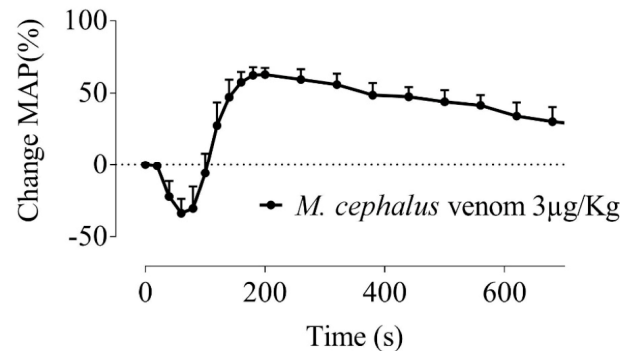

(e)

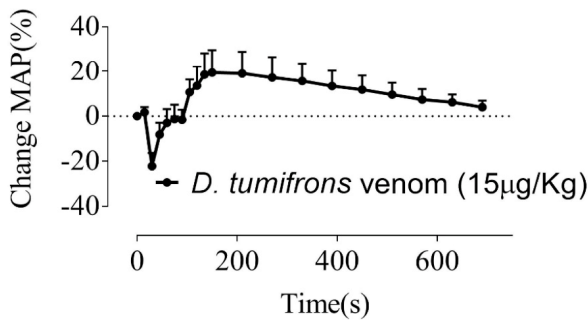

(b)

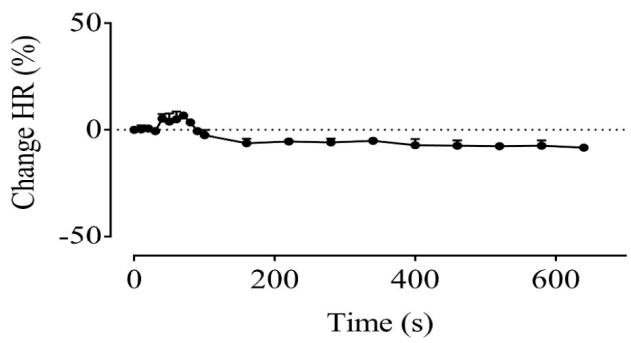

(d)

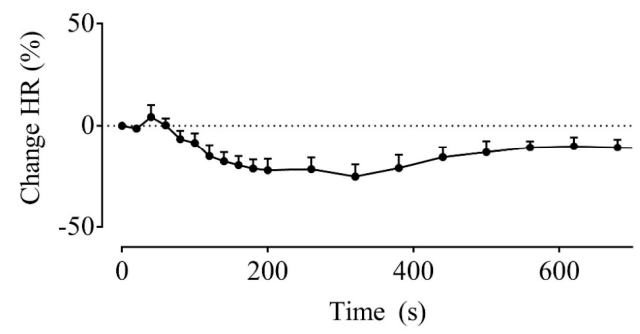

(f)

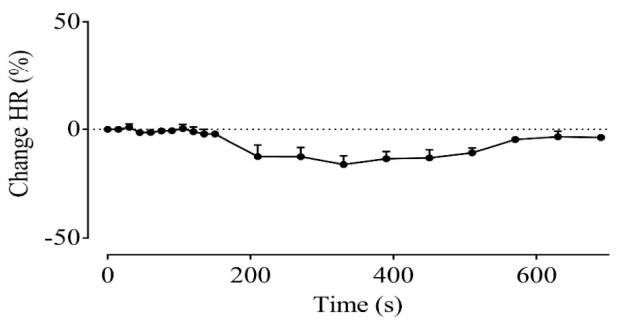

Figure 2. The effect of G. tricuspidata, M. cephalus, and D. tumifrons venoms on mean arterial pressure (MAP; $\mathbf{a}, \mathbf{c}, \mathbf{e}$, respectively) and heart rate $(\mathbf{b}, \mathbf{d}, \mathbf{f}$, respectively) of the anaesthetised rat. $N=3$. Each data point and error bar represents the mean of three experiments and the corresponding SEM.

\subsection{Effects of Crude Venoms on the Chick Biventer Cervicis Nerve-Muscle (CBCNM) Preparation}

The venom of the two stingray species-H. toshi $(0.5-1 \mu \mathrm{g} / \mathrm{mL})$ and $N$. kuhlii $(1-5 \mu \mathrm{g} / \mathrm{mL})$-both abolished indirect twitches of the $\mathrm{CBCNM}$ preparation in a concentration-dependent manner (Figure $3 \mathrm{a}, \mathrm{c})$. Both venoms also significantly inhibited contractile responses to acetylcholine (ACh) and carbachol (CCh), but had no significant effect on responses to $\mathrm{KCl}$ (Figure 3b,d). Similarly, venom from the bony fish P. fuscus $(1-2 \mu \mathrm{g} / \mathrm{mL})$ was also found to abolish the indirect twitches of the CBCNM preparation in a concentration-dependent manner (Figure 3e), and significantly inhibited the contractile response to $\mathrm{ACh}$ and $\mathrm{CCh}$, but not $\mathrm{KCl}$ (Figure 3f). The time taken for twitch height to reduce by $50 \%$ of initial (i.e., $\mathrm{t}_{50}$ ) in response to $1 \mu \mathrm{g} / \mathrm{mL}$ of $N$. kuhlii, $H$. toshi, and P. fuscus venoms was determined. The $t_{50}$ of $H$. tosh $i$ venom was significantly less than that of both $N$. kuhlii and P. fuscus ( $p<0.05$; one-way ANOVA; $N=4$, Table 1). In contrast, G. tricuspidata, M. cephalus, and D. tumifrons venoms induced transient increases in indirect twitches of the CBCNM preparation (Figure $4 \mathrm{a}, \mathrm{c}, \mathrm{e}$ ), and none of these venoms significantly inhibited contractile responses to $\mathrm{ACh}, \mathrm{CCh}$, or $\mathrm{KCl}$ (Figure $4 \mathrm{~b}, \mathrm{~d}, \mathrm{f}$ ). 
(a)

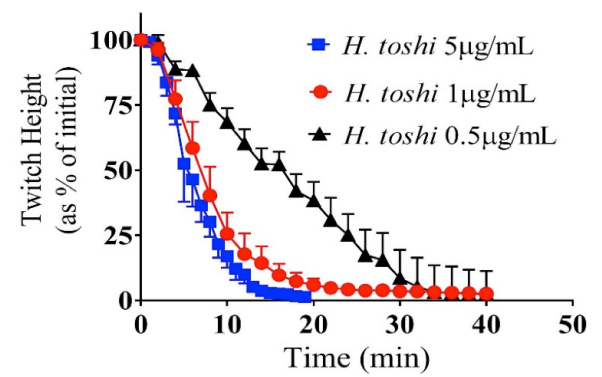

(c)

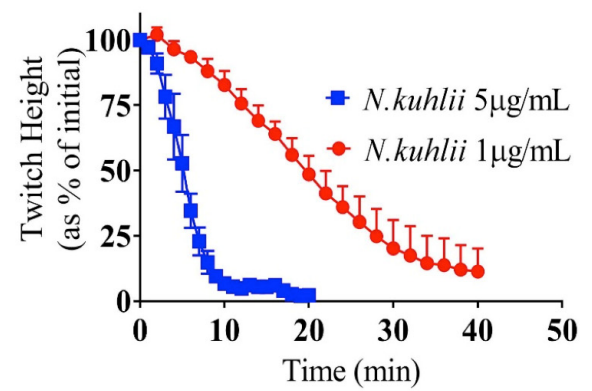

(e)

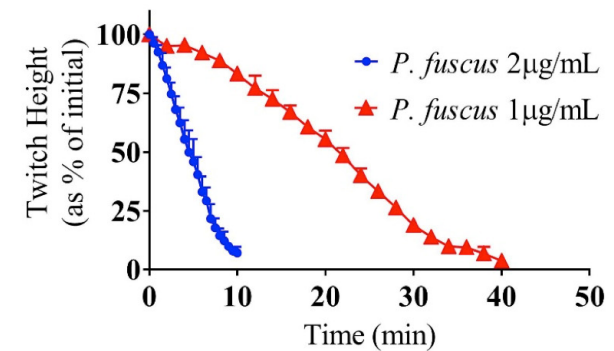

(b)

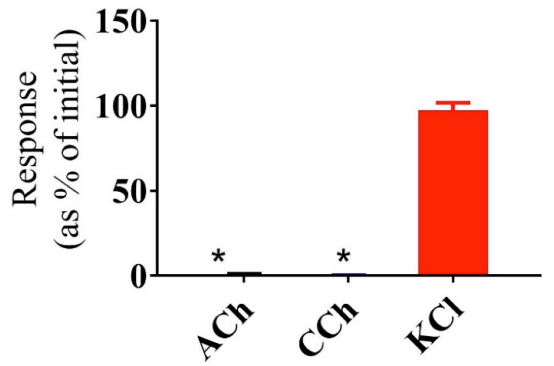

(d)

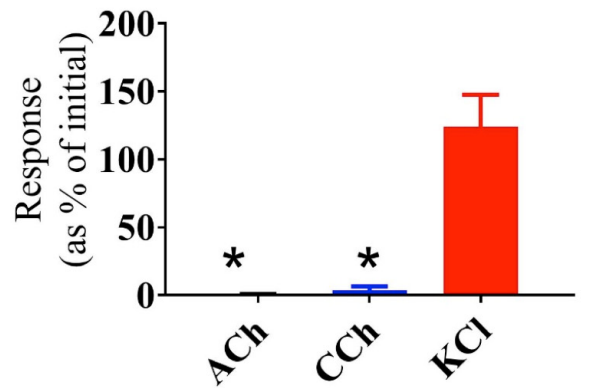

(f)

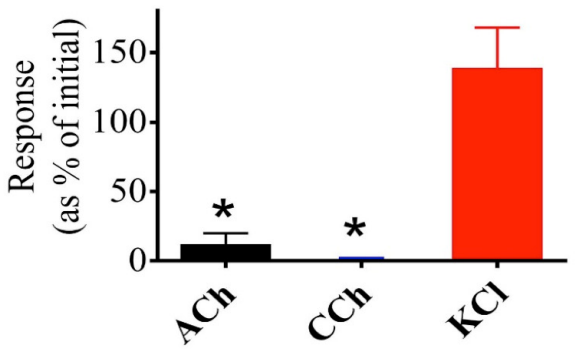

Figure 3. The effect of H. toshi (0.5-5 $\mu \mathrm{g} / \mathrm{mL})$, N. kuhlii (1-5 $\mu \mathrm{g} / \mathrm{mL})$, and P. fuscus $(1-2 \mu \mathrm{g} / \mathrm{mL})$ venom on indirect twitches (a,c,e, respectively), and contractile responses to exogenous acetylcholine (ACh), carbachol (CCh), or $\mathrm{KCl}\left(\mathbf{b}, \mathbf{d}, \mathbf{f}\right.$, respectively) the $\mathrm{CBCNM}$ preparation $N=4 .{ }^{*} p<0.05$, significantly different from the pre-venom baseline, paired $t$-test. Error bars represent the SEM.

Table 1. $T_{50}$ values for fish venoms at $1 \mu \mathrm{g} / \mathrm{mL}$ (mean $\left.\pm \mathrm{SEM}\right)$.

\begin{tabular}{cc}
\hline Species & $\mathbf{t}_{\mathbf{5 0}}$ (min) \\
\hline N. kuhlii & $19 \pm 0.3$ \\
H. toshi & $7 \pm 0.1^{*}$ \\
P. fuscus & $22 \pm 0.2$
\end{tabular}

* Significantly different compared to N. kuhlii and P. fuscus $(p<0.05)$ one-way ANOVA; $N=4$. 
(a)

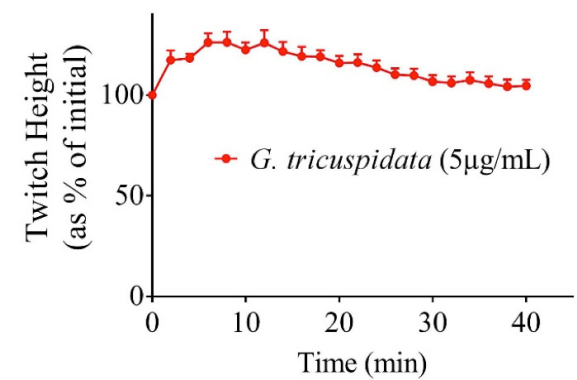

(c)

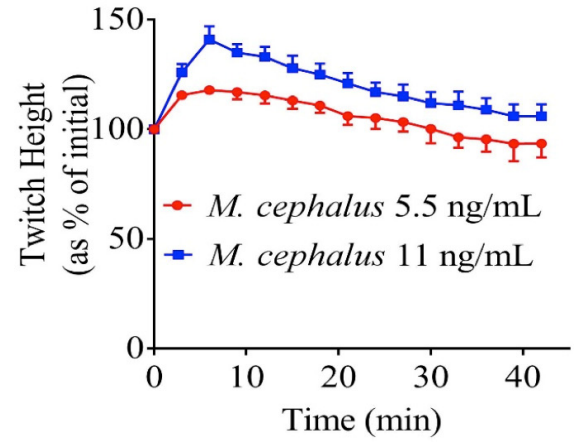

(e)

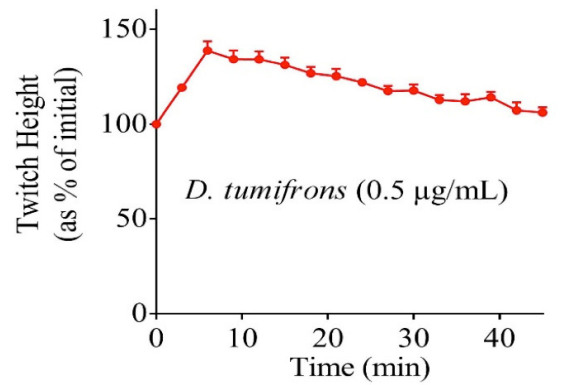

(b)

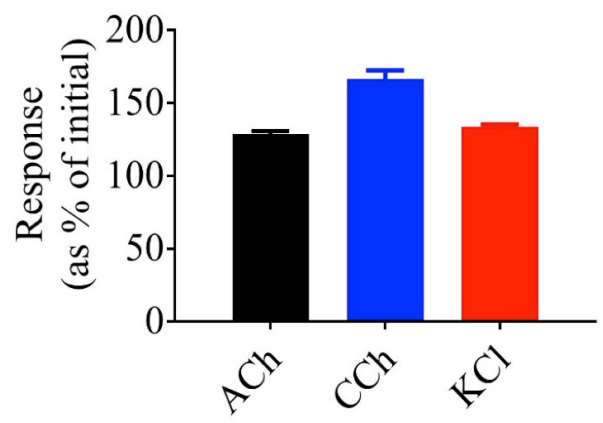

(d)

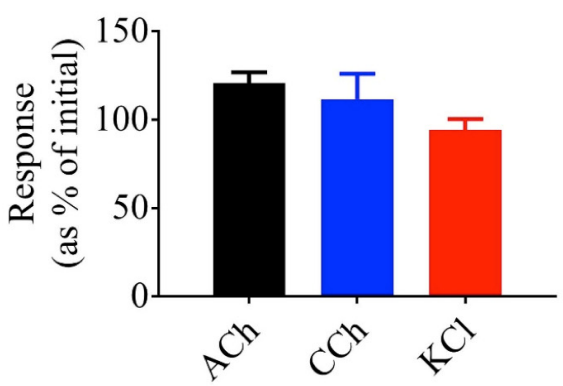

(f)

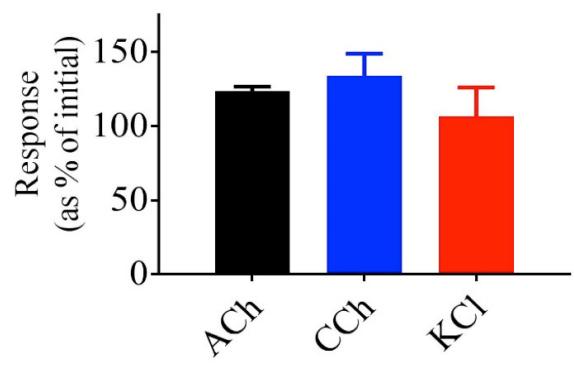

Figure 4. The effect of G. tricuspidata $(5 \mu \mathrm{g} / \mathrm{mL})$, M. cephalus $(5.5-11 \mathrm{ng} / \mathrm{mL})$, and D. tumifrons $(0.5 \mu \mathrm{g} / \mathrm{mL})$ venom on indirect twitches (a,c,e, respectively), and contractile responses to exogenous $\mathrm{ACh}, \mathrm{CCh}$ or $\mathrm{KCl}(\mathbf{b}, \mathbf{d}, \mathbf{f}$, respectively) of the $\mathrm{CBCNM}$ preparation. $N=4$. Error bars represent the SEM.

\section{Discussion}

Fish venoms show enormous diversity and complexity of pharmacologically active components [21]. One of the major clinical symptoms observed in humans after fish envenoming is hypotension with marked cardiovascular activity [11]. In this study, we have examined the effect of several fish venoms on the cardiovascular system of anaesthetised rats, paying particular attention to MAP and HR. We have also examined the in vitro neurotoxic effects of these venoms using an avian skeletal muscle preparation. All venoms examined had some effect on the MAP of anesthetised rats, while only the venoms of N. kuhlii, H. toshi, and P. fuscus displayed in vitro neurotoxicity. Interestingly, three of the venoms potentiated twitch height in the skeletal muscle.

In the anesthetised rat, the venoms from N. kuhlii, H. toshi, and P. fuscus induced an initial decrease in MAP at concentrations of $10-100 \mu \mathrm{g} / \mathrm{kg}$. In the case of $P$. fuscus venom, the MAP returned to baseline. However N. kuhlii and $H$. toshi venoms displayed a biphasic response characterised by an initial drop in blood pressure followed by a sustained pressor response. This biphasic response is similar to results observed in previous studies on the Scorpaeniformes Gymnapistes marmoratus, Pterois volitans, and Synanceia verrucosa [22-24]. The pressoric cardiovascular responses induced by G. marmoratus, P. volitans, and S. verrucosa venoms were thought to involve an activity dependent on adrenoceptors $[22,25,26]$ and / or to be mediated by non-adrenergic mechanisms $[1,27]$. Prior research 
also suggested that the depressor response induced by some fish venoms involved muscarinic receptors and/or nitric oxide synthesis [1,19,27-29]. All three venoms-N. kuhlii, H. toshi, and P. fuscus-induced cardiovascular collapse at $200 \mu \mathrm{g} / \mathrm{kg}$.

Our results indicate that the venom of G. tricuspidata induces a sustained drop in MAP at concentrations as low as $5 \mu \mathrm{g} / \mathrm{kg}$. The venom from M. cephalus $(3 \mu \mathrm{g} / \mathrm{kg})$ and D. tumifrons $(15 \mu \mathrm{g} / \mathrm{kg})$ also induced a biphasic response similar to that observed after administering venom from $N$. kuhlii and $H$. toshi. The limited supply of venom from these three species precluded us from examining their effects at higher concentrations. However, unlike N. kuhlii and H. toshi venoms, M. cephalus and D. tumifrons venoms had a transient negative chronotropic effect on $\mathrm{HR}$, in addition to changes in blood pressure. Previously described chronotropic responses to fish venom have been attributed to different mechanisms, including the activity of chemical mediators in the venom [30], activity on adrenergic and muscarinic receptors [27], or the release of endogenous autacoids in cardiac tissues [22,27,28]. Further studies are required to determine the mechanism(s) responsible for the decrease in HR observed in response to $D$. tumifrons and $M$. cephalus venoms.

Although cardiovascular activity is the most widely reported symptom of fish envenoming, paralysis, muscle spasm, and prolonged weakness have also been noted in envenomed humans [31]. Consequently, we studied the effects of the above-mentioned fish venoms on the skeletal neuromuscular junction, using the chick biventer cervicis nerve-muscle preparation. The venoms from H. toshi, N. kuhlii, and P. fuscus induced a concentration-dependent decrease in indirect twitches of the preparation, with abolition of twitches within $60 \mathrm{~min}$ at the tested concentrations. In addition, all three venoms significantly inhibited responses to the nicotinic agonists $\mathrm{ACh}$ and $\mathrm{CCh}$, but not to $\mathrm{KCl}$. These results are consistent with the presence of postsynaptic neurotoxins in these venoms. Postsynaptic neurotoxins have been shown to bind with high affinity to nicotinic acetylcholine receptors and competitively antagonise the actions of acetylcholine [32]. Similar findings have been described from the venom of the bony fish Scatophagus argus [33]. In contrast, D. tumifrons, G. tricuspidata, and $M$. cephalus venoms did not abolish indirect twitches of the chick biventer cervicis. Instead, these venoms induced a transient potentiating effect with no significant inhibition of the contractile responses to exogenous agonists.

To the best of our knowledge, this is the first study to examine the neurotoxic and cardiovascular effects of the venoms from these six species of fish. The cardiovascular effects as indicated by changes in MAP were apparent across all of the species tested, even at low concentrations. However, in vitro neurotoxicity was only observed in response to H. toshi, N. kuhlii, and P. fuscus venoms. These results corroborate other findings, suggesting that while most fish venoms are convergently functionally similar due to shared selection pressures for their use as defensive weapons, their effects differ quantitatively due to unique components in different venomous fish lineages [15], in addition to the quantity of the venom delivered [31]. Due to the limited amount of pharmacological data available for fish venoms, our results contribute significantly to our understanding of the functional activity of bony and cartilaginous fish venoms. These results have implications spanning evolutionary theory through to the treatment of envenomed patients.

\section{Materials and Methods}

\subsection{Crude Venom}

\subsubsection{Sample Collection and Storage}

Specimens were collected under collection permit QS2013/MAN143 (13/12/13) and animal ethics approval SBS/345/12/ARC (24 December 2015). Spine samples were collected and immediately snap frozen in liquid nitrogen before storage at $-80{ }^{\circ} \mathrm{C}$ until use. 
Chondrichthyes (Cartilaginous Fish)

Himantura toshi (Brown Whipray—collected from Moreton Bay, Queensland) and Neotrygon kuhlii (Bluespot stingray—collected from Moreton Bay, Queensland)

Osteichthyes (Bony Fish)

Dentex tumifrons (Yellowbacked Seabream-collected from Moreton Bay, Queensland Australia), Girella tricuspidata (Luderick Bream—collected from Moreton Bay, Queensland) Mugil cephalus (Flathead Mullet—collected from Moreton Bay, Queensland); and Platycephalus fuscus (Flathead Bream—collected from Mornington Peninsula, Victoria and Moreton Bay, Queensland).

\subsubsection{Protein Extraction}

The crude venom was extracted from the fish spines and cleaned as previously described [5]. A solution was prepared on ice using $3.7 \mathrm{~g}$ EDTA, $5 \mathrm{~mL} 200 \mathrm{mM}$ PMSF, $10 \mathrm{~mL}$ Triton X-100, 1 L purified water. The solution was poured over the spines and placed on a magnetic stirrer overnight $(>12 \mathrm{~h})$ at $4{ }^{\circ} \mathrm{C}$. The solution was then centrifuged at $4500 \mathrm{RCF}, 4{ }^{\circ} \mathrm{C}$ for $30 \mathrm{~min}$, before $80 \%$ ammonium sulphate saturation $(\sim 43 \% w / v)$ was added and the solution placed on a magnetic stirrer at $4{ }^{\circ} \mathrm{C}$ and left overnight ( $>12 \mathrm{~h}$ ). The protein-containing precipitate was then centrifuged at $4500 \mathrm{RCF}, 4^{\circ} \mathrm{C}$ for $30 \mathrm{~min}$. The supernatant was removed, and the protein precipitate brought up in purified water (ratio of 15 parts water to 1 part supernatant), vortexed for $2 \mathrm{~min}$, followed by centrifugation at $14,000 \mathrm{RCF}, 4{ }^{\circ} \mathrm{C}$ for $30 \mathrm{~min}$. Subsequently, the supernatant was diluted 1:9 with cold 1:4 acetone:methanol. The solution was placed at $-20^{\circ} \mathrm{C}$ and allowed to precipitate overnight $(>12 \mathrm{~h})$. The solution was subsequently centrifuged at $14,000 \mathrm{RCF}, 4^{\circ} \mathrm{C}$ for $30 \mathrm{~min}$, and the supernatant was discarded. The pellet was left to evaporate at room temperature for $1 \mathrm{~h}$, then resolubilised in purified water. The total protein concentration was then measured using a Thermo Scientific Nanodrop 2000 Spectrophotometer in A280 mode (Wilmington, DE, USA). Extracted venom proteins were stored at $-80{ }^{\circ} \mathrm{C}$.

\subsection{Cardiovascular Assays}

The effect of venom on blood pressure and heart rate was determined using the previously described anesthetised rat preparation [34]. This procedure was approved by the Monash Animal Research Platform (MARP) Animal Ethics Committee, Monash University, Australia MARP/2014/97 (approved in December 2014).

\subsection{Neurotoxicity Assays}

The in vitro neurotoxicity of venoms was tested using the chick biventer cervices nerve-muscle preparation as described previously [35,36]. This procedure was approved by the Monash Animal Research Platform (MARP) Animal Ethics Committee, Monash University, Australia MARP/2014/97 (approved in December 2014).

Acknowledgments: This research was funded by the Australian Research Council and the Herman Slade Foundation. Kate Baumann, Jordan Debono, and Ivan Koludarov were the recipients of post-graduate scholarships from the University of Queensland. Nicholas R. Casewell was funded by a UK Natural Environment Research Council Postdoctoral Research Fellowship. Scott C Cutmore was funded by an ABRS National Taxonomy Research Grant.

Author Contributions: B.G.F. and S.K. conceived and designed the experiments; H.H., K.B., N.R.C., S.A.A., Jam.D., I.K., Jor.D., S.C.C., N.W.R., T.N.W.J., R.J., W.C.H., B.G.F. and S.K. performed the experiments; H.H., K.B., N.R.C., S.A.A., Jam.D., I.K., Jor.D., S.C.C., N.W.R., T.N.W.J., R.J., W.C.H., B.G.F. and S.K. analyzed the data; H.H., K.B., N.R.C., S.A.A., Jam.D., I.K., Jor.D., S.C.C., N.W.R., T.N.W.J., R.J., W.C.H., B.G.F. and S.K. all contributed to the writing of the paper.

Conflicts of Interest: The authors declare no conflict of interest and the founding sponsors had no role in the design of the study; in the collection, analyses, or interpretation of data; in the writing of the manuscript, and in the decision to publish the results. 


\section{References}

1. Church, J.E.; Hodgson, W.C. The pharmacological activity of fish venoms. Toxicon 2002, 40, $1083-1093$. [CrossRef]

2. Smith, W.L.; Wheeler, W.C. Venom evolution widespread in fishes: A phylogenetic road map for the bioprospecting of piscine venoms. J. Hered. 2006, 97, 206-217. [CrossRef] [PubMed]

3. Smith, L.; Stern, J.H.; Girard, M.G.; Davis, M.P. Evolution of venomous cartilaginous and ray-finned fishes. Integr. Comp. Biol. 2016, 56, 950-961. [CrossRef] [PubMed]

4. Wright, J. Diversity, phylogenetic distribution, and origins of venomous catfishes. BMC Evol. Biol. $2009,9$. [CrossRef] [PubMed]

5. Baumann, K.; Casewell, N.R.; Ali, S.A.; Jackson, T.N.W.; Vetter, I.; Dobson, J.S.; Cutmore, S.C.; Nouwens, A.; Lavergne, V.; Fry, B.G. A ray of venom: Combined proteomic and transcriptomic investigation of fish venom composition using barb tissue from the blue-spotted stingray (Neotrygon kuhlii). J. Proteom. 2014, 109, 188-198. [CrossRef] [PubMed]

6. King, G.F. Venoms as a platform for human drugs: Translating toxins into therapeutics. Expert Opin. Biol. Ther. 2011, 11, 1469-1484. [CrossRef] [PubMed]

7. Helfman, G.S. The Diversity of Fishes: Biology, Evolution, and Ecology; Blackwell: Oxford, UK, 2009.

8. Casewell, N.R.; Wüster, W.; Vonk, F.J.; Harrison, R.A.; Fry, B.G. Complex cocktails: The evolutionary novelty of venoms. Trends Ecol. Evol. 2013, 28, 219-229. [CrossRef] [PubMed]

9. Borondo, J.C.; Sanz, P.; Nogué, S.; Poncela, J.L.; Garrido, P.; Valverde, J.L. Fatal weeverfish sting. Hum. Exp. Toxicol. 2001, 20, 118-119. [CrossRef] [PubMed]

10. Church, J.E.; Hodgson, W.C. Stonefish (Synanceia trachynis) antivenom: In vitro efficacy and clinical use. J. Toxicol. Toxin Rev. 2003, 22, 69-76. [CrossRef]

11. Sivan, G. Fish venom: pharmacological features and biological significance. Fish Fish 2009, 10, $159-172$. [CrossRef]

12. Smith, J. A case of poisoning by the stonefish, Synanceja verrucosa. Copeia 1951. [CrossRef]

13. Williamson, J.; Fenner, P.J.; Burnett, J.W.; Rifkin, J.F. Venomous and Poisonous Marine Animals: A Medical and Biological Handbook; UNSW Press: Kensington, NSW, Australia, 1996.

14. Andrew, M.E.; Cyril, F.R.; Santosh, P.; Kitmun, H.; Christine, A.O.; Kelly, L.W.; Michelle, A.D.; Wayne, C.H.; Jamie, S.; Peter, K.D.; Rodney, K.T.; James, C.W.; Sheena, M. Stonefish toxin defines an ancient branch of the perforin-like superfamily. Proc. Natl. Acad. Sci. 2015, 112. [CrossRef]

15. Church, J.E.; Hodgson, W.C. Dose-dependent cardiovascular and neuromuscular effects of stonefish (Synanceja trachynis) venom. Toxicon 2000, 38, 391-407. [CrossRef]

16. Ghadessy, F.J.; Chen, D.; Kini, R.M.; Chung, M.C.; Jeyaseelan, K.; Khoo, H.E.; Yuen, R. Stonustoxin is a novel lethal factor from stonefish (Synanceja horrida) venom. cDNA cloning and characterization. J. Biol. Chem. 1996, 271, 25575-25581. [PubMed]

17. Khoo, H.; Yuen, R.; Poh, C.; Tan, C. Biological activities of Synanceja horrida (stonefish) venom. Natural Toxins 1992, 1, 54-60. [CrossRef] [PubMed]

18. Khoo, H.E. Bioactive proteins from stonefish venom. Clin. Exp. Pharmacol. Physiol. 2002, 29, 802-806. [CrossRef] [PubMed]

19. Low, K.S.Y.; Gwee, M.E.; Yuen, R.; Gopalakrishnakone, P.; Khoo, H.E. Stonustoxin: A highly potent endothelium-dependent vasorelaxant in the rat. Toxicon 1993, 31, 1471-1478. [CrossRef]

20. Poh, C.H.; Yuen, R.; Khoo, H.E.; Chung, M.; Gwee, M.; Gopalakrishnakone, P. Purification and partial characterization of stonustoxin (lethal factor) from Synanceja horrida venom. Comp. Biochem. Physiol. B Comp. Biochem. 1991, 99, 793-798. [CrossRef]

21. Magalhães, G.S.; Junqueira-de-Azevedo, I.L.M.; Lopes-Ferreira, M.; Lorenzini, D.M.; Ho, P.L.; Moura-da-Silva, A.M. Transcriptome analysis of expressed sequence tags from the venom glands of the fish Thalassophryne nattereri. Biochimie 2006, 88, 693-699. [CrossRef] [PubMed]

22. Hopkins, B.J.; Hodgson, W.C. Cardiovascular studies on venom from the soldierfish (Gymnapistes marmoratus). Toxicon 1998, 36, 973-983. [CrossRef]

23. Saunders, P.R. Venom of the stonefish Synanceja verrucosa. Science 1959, 129, 2272-2274. [CrossRef]

24. Saunders, P.R.; Taylor, P.B. Venom of the lionfish Pterois volitans. Am. J. Physiol. 1959, 197, 437-440. [PubMed] 
25. Auddy, B.; Alam, M.I.; Gomes, A. Pharmacological actions of the venom of the Indian catfish (Plotosus canius Hamilton). Indian J. Med. Res. 1994, 99, 47-51. [PubMed]

26. Carlson, R.W.; Schaeffer, R.C.; Whigham, H.; Weil, M.H.; Russell, F.E. Some pharmacological properties of the venom of the scorpionfish Scorpaena guttata-II. Toxicon 1973, 11, 167-180. [CrossRef]

27. Church, J.E.; Hodgson, W.C. Adrenergic and cholinergic activity contributes to the cardiovascular effects of lionfish (Pterois volitans) venom. Toxicon 2002, 40, 787-796. [CrossRef]

28. Carlson, R.W.; Schaeffer, R.C.; La Grange, R.G.; Roberts, C.M.; Russell, F.E. Some pharmacological properties of the venom of the scorpionfish Scorpaena guttata-I. Toxicon 1971, 9, 379-391. [CrossRef]

29. Rodrigues, R.J. Pharmacology of South American freshwater stingray venom (Potamotrygon motoro). Trans. N. Y. Acad. Sci. 1972, 34, 677-686. [CrossRef] [PubMed]

30. Hopkins, B.J.; Hodgson, W.C.; Sutherland, S.K. Evidence for adrenergic and tachykinin activity in venom of the stonefish (Synanceja trachynis). Toxicon 1996, 34, 541-554. [CrossRef]

31. Saunders, P.R. Pharmacological and chemical studies of the venom of the stonefish (genus Synanceja) and other scorpion fishes. Ann. N. Y. Acad. Sci. 1960, 90, 798-804. [CrossRef] [PubMed]

32. Barber, C.M.; Isbister, G.K.; Hodgson, W.C. Classic toxin review: Alpha neurotoxins. Toxicon 2013, 66, 47-58. [CrossRef] [PubMed]

33. Muhuri, D.; Karmakar, S.; Dasgupta, S.C.; Nagchaudhuri, A.K.; Gomes, A. Pharmacological studies on the venomous spotted butterfish (Scatophagus argus Linn) sting extract on experimental animals. Indian J. Exp. Biol. 2004, 42, 461-467. [PubMed]

34. Chaisakul, J.; Isbister, G.K.; O’Leary, M.A.; Parkington, H.C.; Smith, A.I.; Hodgson, W.C.; Kuruppu, S. Prothrombin activator-like toxin appears to mediate cardiovascular collapse following envenoming by Pseudonaja textilis. Toxicon 2015, 102, 48-54. [CrossRef] [PubMed]

35. Rusmili, M.R.; Yee, T.T.; Mustafa, M.R.; Hodgson, W.C.; Othman, I. Isolation and characterization of a presynaptic neurotoxin P-elapitoxin-Bf1a from Malaysian Bungarus fasciatus venom. Biochem. Pharmacol. 2014, 91, 409-416. [CrossRef] [PubMed]

36. Silva, A.; Kuruppu, S.; Othman, I.; Goode, R.J.; Hodgson, W.C.; Isbister, G.K. Neurotoxicity in Sri Lankan Russell's viper (Daboia russelii) envenoming is primarily due to U1-viperitoxin-Dr1a, a pre-synaptic neurotoxin. Neurotox. Res. 2017, 31, 11-19. [CrossRef] [PubMed] 